\title{
Review of Remote Terminal Unit (RTU) and Gateways for Digital Oilfield delpoyments
}

\author{
Francis Enejo Idachaba \\ Department of Electrical and Information Engineering \\ Covenant University Ota. \\ Ogun state \\ Nigeria
}

\author{
Ayobami Ogunrinde \\ SPDC Nigeria
}

\begin{abstract}
The increasing decline in easy oil has led to an increasing need for the optimization of oil and gas processes. Digital oilfields utilize remote operations to achieve these optimization goals and the remote telemetry unit and gateways are very critical in the realization of this objective. This paper presents a review of the RTUs and gateways utilized in digital oilfield architectures. It presents a review of the architecture, their functionality and selection criteria. It also provides a comparison of the specifications of some popular RTUs.
\end{abstract}

Keywords-Digital Oilfield; Gateway; HMI; i-fields; RTU; Smartfields.

\section{INTRODUCTION}

The advent of Digital Oilfields, Smartfields or i-fields has led to an increase in the need to monitor, control and automate various systems at remote oil and gas production sites to increase production, reduce overall production cost, and reduce employee exposure. Control systems such as SCADA (Supervisory Control and Data Acquisition), or DCS (Distributed Control System) using Remote Telemetry Units and Gateways are deployed to achieve these control functions. The RTUs and gateways comprises of various components such as

- $\quad$ HMI (Human Machine Interface)

- RTU (Remote Terminal Unit): This collects the site data and sends it to a station via a communications system.

- Supervisory systems/ Master station: this collects the information from the process and control the process. This is usually a computer.

- Communication system that provides a means by which all components communicate securely without loss of data and information.

Digital oilfield installations require bidirectional transmission of data from the sensors located in the field and control signals from the control room or the office domain to these sensors and devices located in the field. The data from the sensors are transmitted at defined intervals or by exception while the control algorithms used for the field devices can either be the on/off control or a variable control. This paper Ease of Use
II. RTU

Remote Terminal Unit (RTU) is a microprocessor-based device connected to sensors, transmitters or process equipment for the purpose of remote telemetry and control.

RTUs find applications in oil and gas remote instrumentation monitoring, networks of remote pump stations, Environmental monitoring systems, Air traffic equipment etc. [1]

RTUs with the aid of appropriate sensors, monitors production processes at remote site and transmits all data to a central station where it is collated and monitored. An RTU can be interfaced using serial ports (RS232, RS482, and RS422) or Ethernet to communicate with the central stations. They also support various protocol standards such as Modbus, IEC 60870, DNP3 making it possible to interface with 3rd party software.

\section{RTU ARCHITECTURE}

The RTU architecture comprises of a CPU, volatile memory and nonvolatile memory for processing and storing programs and data. It communicates with other devices via either serial ports or an onboard modem with I/O interfaces. It has a power supply with a backup battery, surge protection against spikes, real-time clock and a watchdog timer to ensure that it restarts when operating in the sleep mode.[2]

Figure 1 shows the block diagram of a typical RTU configuration. A typical RTU hardware module includes a control processor and associated memory, analog inputs, analog outputs, counter inputs, digital inputs, digital outputs, communication interfaces and power supply [3]

\section{A. Central Processing Unit (Срu)}

Current RTU designs utilize a 16bit or 32 bits microprocessor with a total memory capacity of $256 \mathrm{kbytes}$ expandable to 4 Mbytes. It also has two or three communication ports (RS232, RS422 and RS485) or Ethernet link. This system is controlled by a firmware and a real-time clock with full calendar is used for accurate time stamping of events. A watchdog timer provides a check that the RTU program is executing regularly. The RTU program regularly resets the watchdog timer and if this is not done within a 


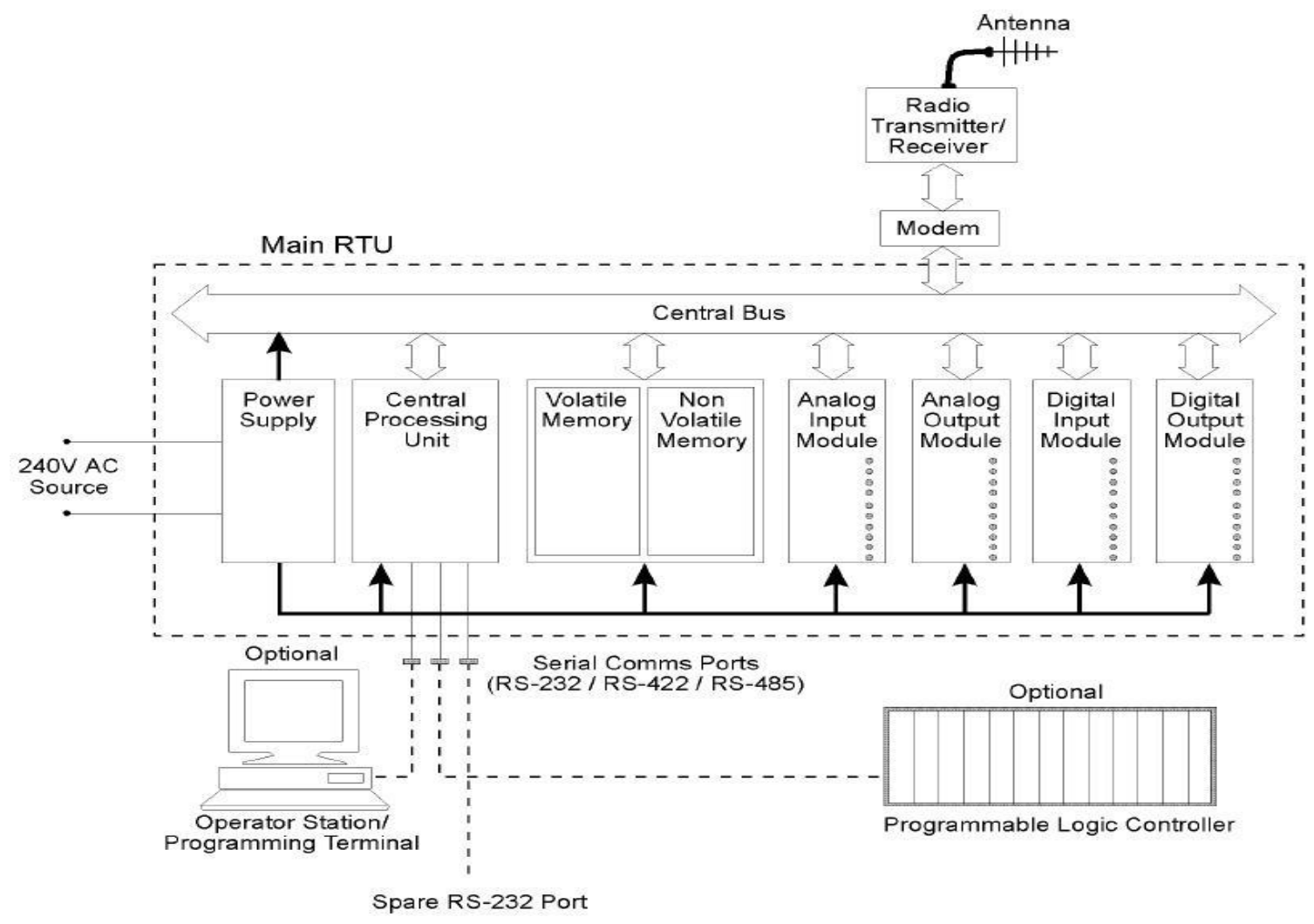

Figure. 1 RTU Hardware Structure [3]

\section{B. Analog Input Modules}

An analog input signal is generally a voltage or current that varies over a defined value range, in direct proportion to a physical process measurement. 4-20 milliamp signals are most commonly used to represent physical measurements like pressure, flow and temperature. [4]. Five main components that makes up the analog input module are as follows:

- Input multiplexer: This samples several analog inputs in turn and switches each to the output in sequence. The output goes to the analog digital converter.

- Input signal amplifier: This amplifies the low-level voltages to match the input range of the board's A/D converter

- Sample and hold circuit

- $\quad \mathrm{A} / \mathrm{D}$ converter: This measures the input analog voltage and output a digital code corresponding to the input voltages.

- Bus interface and board timing system.

Typical analog input modules features include:

- 8,16 , or 32 analog inputs

- Resolution of 8 to 12 bits

- Range of 4-20 mA

- Input resistance typically 240kohms to $1 \mathrm{Mohms}$
- Conversion rates typically 10 microseconds to 30 milliseconds.

\section{Analog Output Module}

Analog Output modules function is to convert a digital value supplied by the CPU to an analog value by means of a digital to analog converter. This analog representation can be used for variable control of actuators.

Analog output modules features are as follow:

- 8,16 or 32 analog outputs

- Resolution of 8 or 12 bits

- Conversion rate from $10 \mu$ seconds to 30 milliseconds

- Outputs ranging from $4-20 \mathrm{~mA} / 0$ to 10 volts

D. Digital Input Modules

These are used to indicate status and alarm signals [5]

E. Digital Output Modules

These modules are used to drive an output voltage at each of the appropriate output channels with three approaches possible.

- Triac Switching: Triacs are used to achieve AC power control. The Triac responds primarily as a switch, the AC energy source for a portion of each alternation can be controlled [6]

- $\quad$ Read Relay Switching 
- $\quad$ TTL voltage outputs

\section{F. Power Supply Module}

RTUs need a continuous power supply to function, but there are situations where RTUs are located at quite a distance from an electric power supply. In these cases, RTUs are equipped with alternate power source and battery backup facilities in case of power losses.

Solar panels are commonly used to power low-powered RTUs, due to the general availability of sunlight. Thermo electric generators can also be used to supply power to the RTUs where gas is easily available like in pipelines. [4]

\section{G. Communication interfaces}

Modern RTU are designed to be flexible enough to handle multiple communication media such as

- $\quad \mathrm{RS} 232 / \mathrm{RS} 442 / \mathrm{RS} 485$

- $\quad$ Ethernet

- Dial up telephone lines/dedicated landlines

- Mircrowave/MUX

- Satellite

- X.25 packet protocols

- Radio via trunked/VHF/UHF/900 Mhz

\section{GATEWAY}

A gateway is a device with dedicated hardware and software that translates between two different protocols, making communication possible between networks of different architectures and protocols. The job of a gateway is much more complex than that of a network router or switch due to this conversion functions. Gateways in digital oil fields collate data from the RTUs in the field and remote sites and integrate these data into the Companies IT network

Gateways are necessary for communication between terminals connected to heterogeneous networks using different protocols and having different network characteristics. They provide the connectivity between systems at remote locations with the target system to enable different network applications

A gateway can function as a protocol gateway which converts between protocols; an application gateway which accepts inputs in one format translates it and then sends it, or a security gateway which basically acts as a firewall securing and filtering packets. [7]

Components of a gateway

- Microprocessor

- Motherboard

- RAM

- Flash

- Interface boards as I/O ports

\section{SELECTING THE RIGHT EQUIPEMENT}

The selection of RTUs and Gateways are based on the specifications of the implementation in terms of data type, capacity and transmission rate. These parameters include [8]
1) Capacity: The RTU must be able to support the data transmission frequency and the data rates. The RTU must also have sufficient spare IOs to allow for expansion.

2) Environment Factor: The RTU must be able to withstand the environmental factors and be designed to the required ingress protection ratings and installed in the appropriate hazardous area classification.

3) Control: RTUs are also used for applications requiring different control schemes such as on/off and variable control. Control relays serve as the control element and are connected to the RTU and activated remotely to achieve the desired control. During RTU selection, the type of control required must be defined to ensure that the selected RTU supports the control system.

4) Connectivity: The network connectivity requirements and data formats must defined before the RTU and Gateways are selected. The data exchange format must also be defined before the selection of the RTU and gateways are finalized.

5) Upgradeability: The ease of firmware upgrade is also another key parameter as it will be desired for the RTU and gateway to be upgradeable over the air without the requirement of un-installation and office based upgrade.

6) Transmission range: The RTU frequency and range are to be confirmed to be suitable for the application and this is usually confirmed by network plan. The equipment are expected to operate within the approved frequency band and with the required licenses.

7) Power: The power supply requirements should also be within the required capacity and quality and these power supply systems must be able to with stand the environmental factors, cost and weather conditions and also be resistant to vandalization. Options include solar panels, batteries or other power source. Also putting into consideration cost as well.

\section{RTU MANUFACTURERS}

There are various manufacturers of Remote Terminal Unit for various functions and industries. A list of some RTU manufactures and their products are presented in the Table 1

1) Vmonitor $\mathrm{iX}-\mathrm{S} 8$ Wireless RTU: An intelligent remote terminal unit and wireless technology with low power consumption to provide a reliable and cost effective means of remotely monitor and automate your applications in the oil and gas fields. [9]

2) ControlWave $\AA$ Micro Hybrid RTU/PLC: A highly programmable controller that combine the unique capabilities of a programmable logic controller (PLC) and a remote terminal unit (RTU) into a single hybrid controller. [10]

3) Zetron Model 1732 RTU: A cost-effective solution for applications that need to connect widely distributed remote sites to a central control program using radio, telephone and wire line communications media. [11]

4) Brodersen RTU32: Brodersen RTU32 RTU, PLC and controller series based on a 32-bit platform provides RTU/PLC with power and leading edge functionality. [12] 
5) Siemens Vicos RTU: A telecontrol with standard SIMATIC S7 Programmable Logic controller [13]

6) Oleumtech Wireless RTU/Modbus Gateway: Wio wireless RTU products are low cost remote terminal units that combine traditional remote IO functionality of a standard [14]

\section{REFERENCES}

[1] Borin Manifacturing. Borin Manifacturing, Inc. Borin [online] http://www.borin.com/remote-terminal-unit/. [Accessed 24 July 2012]

[2] TheWater Environment Federation, "Automation of waste water treatment facilities." WEF Press McGraw-Hill Companies, 2007.

[3] Clarke, G.R., Reynders,D and Edwin W, "SCADA protocols: DNP3, 60870.5 and related systems." Elsevier, 2004. pp. 15 - 25

[4] Shaw, W.T. "Cybersecurity for SCADA systems." Pennwell books, 2006. pp. 25 - 32

[5] Sumathi S. and Surekha..P. "LabVIEW based advances instrumentation sustems.” Springer, 2007. pp 242 - 246

[6] Patrick, D.R. and Fardo, S.W. Electricity and electronics fundamentals.: Fiarmont Press, Inc, 2008.
[7] Zhang, P and William A. "Advnced Industrial Control Technology." 2010. pp $378-379$

[8] DPS Telecom. [online] http://www.dpstele.com. [Accessed 24 $4^{\text {th }}$ July 2012]

[9] VMonitor. VMonitor.[online] http://www.vmonitor.com. [Accessed $24^{\text {th }}$ July 2012]

[10] Emerson Process Mangement. [Online] http://www.documentation.emersonprocess.com [Accessed $24^{\text {th }}$ July 2012]

[11] Zetron. [online] http://www.zetron.com. [Accessed 24 $4^{\text {th }}$ July 2012]

[12] Borderson. [online] http://brodersensystems.com. [Accessed $24^{\text {th }}$ July 2012]

[13] Siemens. [Online] https://concert.siemens.com. [Accessed 24 ${ }^{\text {th }}$ July 2012]

\section{AUTHORS PROFILE}

Francis Idachaba (idachabafe@yahoo.com) a lecturer with Covenanrt University Ota is currently with on a Fellowship with Shell Petroleum Development Company in Nigeria.

Ayobami Ogunrinde (ayo.ogunrinde@gmail.com ) is currently with SPDC in Nigeria.

TABLE 1. RTU MANUFATURERS SPECIFICATION

\begin{tabular}{|c|c|c|c|c|c|}
\hline & Vmonitor iX-S8 & $\begin{array}{c}\text { Control Wave Micro } \\
\text { Hybrid }\end{array}$ & $\begin{array}{l}\text { Zetron } 1732 \\
\text { RTU }\end{array}$ & Broderson RTU 32 & $\begin{array}{c}\text { Siemens } \\
\text { Vicos RTU }\end{array}$ \\
\hline Processor & $\begin{array}{c}8051 \text { Micro- } \\
\text { Controller running at } \\
\text { 12.58Mhz 64KB } \\
\text { Data Memory } \\
\end{array}$ & $\begin{array}{l}\text { 32-bit ARM 9 Processor, } 33 \mathrm{MHz} \\
\text { CPU Module (Low power) } 150 \\
\text { MHz Module }\end{array}$ & PLC & $\begin{array}{l}\text { 32-bit 500 Mhz CPU } \\
\text { with } 128 \mathrm{~K} \text { L2 Cache }\end{array}$ & $\begin{array}{c}\text { SIMATIC S7 - } \\
300 \text { Central Units }\end{array}$ \\
\hline Serial Port & $\begin{array}{c}\text { RS232 } \\
\text { RS232/RS485 } \\
\text { I2C }\end{array}$ & $\begin{array}{c}\text { RS232 } \\
\text { RS485 } \\
\text { Ethernet }\end{array}$ & RS232 & $\begin{array}{c}\text { Dual Ethernet } \\
\text { RS232 } \\
\text { RS232/RS422/RS485 } \\
\text { USB }\end{array}$ & $\begin{array}{c}\text { RS232 } \\
\text { Ethernet }\end{array}$ \\
\hline Comm. Protocol & $\begin{array}{l}\text { Vmonitor Proprietary } \\
\text { Protocol } \\
\text { MODBUS }\end{array}$ & $\begin{array}{c}\text { MODBUS, Foundation Fieldbus. } \\
\text { HART, DFI, CIP, DNP3, Serial } \\
\text { ASCII }\end{array}$ & MODBUS & $\begin{array}{l}\text { MODBUS, DNP3 Suite, } \\
\text { ProfiNET Client, } \\
\text { PROFIBUS DP Master, } \\
\text { COMLI, IEC 61400-25 }\end{array}$ & $\begin{array}{c}\text { IEC60870-5, } \\
\text { SINAUT8-FW } \\
\text { PCM, } \\
\text { Profibus, } \\
\text { ProfiNET } \\
\end{array}$ \\
\hline Operation Modes & $\begin{array}{c}\text { Continuous, Stand } \\
\text { alone and Sleep } \\
\text { Mode } \\
\end{array}$ & $\begin{array}{l}\text { Run Mode, Remote Mode, Local } \\
\text { Mode and Sleep Mode for Low } \\
\text { power application }\end{array}$ & Fail-Safe Mode & & \\
\hline Radio & $900 \mathrm{MHz}$ or $2.4 \mathrm{GHz}$ & & $902-928 \mathrm{MHz}$ & & $902-928 \mathrm{MHz}$ \\
\hline Distance & Up to 5 Miles & & & & \\
\hline $\begin{array}{l}\text { Operating } \\
\text { Temperature }\end{array}$ & $\begin{array}{c}(-40 \text { to } 85)^{\circ} \mathrm{C} \\
\text { Humidity }(5-90 \%)\end{array}$ & $(-40 \text { to } 70)^{\circ} \mathrm{C}$ Humidity $(15-95 \%)$ & $\begin{array}{c}(0 \text { to } 50)^{\circ} \mathrm{C} \\
\text { Humidity }(0- \\
90 \%) \\
\end{array}$ & $(-40 \text { to } 70)^{\circ} \mathrm{C}$ & $\begin{array}{c}(0 \text { to } 60)^{\circ} \mathrm{C} \\
\text { Humidity }(5- \\
95 \%) \\
\end{array}$ \\
\hline Power Supply & $\begin{array}{l}\text { Input Power 8- } \\
\text { 15VDC (Battery } \\
\text { Powered) }\end{array}$ & $9-30 \mathrm{VDC}$ & $\begin{array}{c}\text { 16VDC 2A } \\
\text { Max, 120 VAC }\end{array}$ & $\begin{array}{c}24-48 \mathrm{VDC} \\
115-230 \mathrm{VAC} / \mathrm{DC} \\
115-230 \mathrm{VAC} / \mathrm{DC} \text { with } \\
\text { UPS and Battery } \\
\end{array}$ & $\begin{array}{l}\text { 24VDC, } 230 \\
\text { VAC }\end{array}$ \\
\hline $\begin{array}{c}\text { Integrated } \\
\text { Analogue/Digital } \\
\text { Input }\end{array}$ & $\begin{array}{l}\text { (AI): } 1-5 \mathrm{~V}, 4-20 \mathrm{~mA} \\
\text { (DI): } 3-24 \mathrm{VAC}\end{array}$ & $\begin{array}{l}\text { (AI): } 1-5 \mathrm{~V}, 4-20 \mathrm{~m} \mathrm{~A} \\
\text { (DI): } 12-24 \mathrm{VDC}\end{array}$ & $\begin{array}{c}\text { (AI): +/- } 10 \\
\text { VDC, } 4-20 \mathrm{~mA}\end{array}$ & $\begin{array}{c}\text { (AI): } 0-10 \mathrm{~V}, 0-5 \mathrm{~V},+/- \\
5 \mathrm{~V},+/-10 \mathrm{~V}, 0-20 \mathrm{~mA}, 4- \\
20 \mathrm{~mA} \\
\text { (DI): } 10-30 \mathrm{VDC}\end{array}$ & \\
\hline
\end{tabular}

